\title{
Power Factor Correction Using Fuzzy Logic Control
}

\author{
P.Kripakaran ${ }^{1}$, J.Sathishkumar ${ }^{2,}$ R.Gopi Krishna ${ }^{3}$ \\ ${ }^{I}$ (Asst.Prof, EEE, Rajiv Gandhi College of Engineering and Technology, Puducherry, kripa_pt@yahoo.co.in) \\ ${ }^{2}$ (Asst.Prof EEE, Rajiv Gandhi College of Engineering and Technology, Puducherry, jskumar9898@gmail.com) \\ ${ }_{3}^{3}$ (Asst.Prof, EEE, Rajiv Gandhi College of Engineering and Technology, Puducherry, gopi_pec@yahoo.com)
}

\begin{abstract}
Harmonic pollution and low power factor in power systems caused by power converters have been a great concern. To overcome these problems several converter topologies and control schemes have been proposed in recent years. This paper is proposed to study the control techniques for such converters to improve the Power Factor $(P F)$ and reduce total harmonic distortion (THD) in the input current with output voltage regulation. A new fuzzy logic control strategy for boost PFC is presented in this paper. Here the controlling action was established through a fuzzy Logic controller. The proposed Fuzzy Logic control system is a two input one output Fuzzy Logic Controller. The proposed PFC control is derived based on Boost converter operates at continuous conduction mode and the switching frequency is much higher than the line frequency so that input voltage can be assumed as a constant during one switching cycle.
\end{abstract}

Keywords: Power Factor Correction, Total Harmonic Distortion, Boost Converter, Fuzzy Control

\section{Introduction}

In most power electronic applications, the power input is of 50 or 60 hertz $\mathrm{AC}$ voltage provided by the electric utility [1]. It further converted to a DC voltage for various applications. The inexpensive rectifiers with diodes convert $\mathrm{AC}$ to $\mathrm{DC}$ and the output voltage is uncontrolled. The controlled rectifiers are used for providing variable/ constant output voltage. The dc output voltage of a controlled/uncontrolled rectifier should be ripple free. Therefore a large capacitor is connected as a filter on dc side. Due to this, controlled/uncontrolled rectifier has the following drawbacks. These rectifiers draw highly distorted current from the utility, Power factor is very low.

In high power rectifiers Switch mode AC-DC converters are being used as front end rectifiers for variety of applications due to the advantage of high efficiency and power density [2]. These switched mode ac to de converters, also draw non sinusoidal input current with low power factor and high harmonics content. . This has led to the consistent research to improve the performance of various conversion system and hence new topologies for switch mode power factor corrected AC to DC converter. The switch mode power factor corrected AC to DC converter has been in two directions namely, buck and boost type topologies. The advantage of Buck type topology is that converter can provide variable output voltage, which is lower than the input voltage. However when the instantaneous input voltage is below the output voltage the current drops to zero, and the results in significant increase in THD of the input current. The boost type converter is capable of producing the output de voltage which is higher than the input ac voltage. The input current in these converters flows through the boost inductor which helps to wave shape using appropriate current control strategies. Hence boost converters not only provide regulated dc output voltage but also maintained near unity power factor and reduce THD of the input current. The boost type converters with various topologies have found wide spread use in various applications due to its advantages such as high efficiency, high power density and inherent power quality improvement at input and output.

\section{Current Control Techniques For Pfc Converters}

The current control techniques have gained importance in ac to dc converters used for high performance applications. Where the fast response and high accuracy are important. Various current control methods have been proposed and classified as hysteresis control, linear control and predictive control. Principle of these methods are briefly described and discussed below.

\subsection{Hysteresis Control}

Hysteresis current control [3] is an instantaneous feedback control system which uses the current error when exceeds the limit of the band, the switches are turned on/off. The advantage of this technique is simple, accurate, and robust. Also, the speed of the response is limited by switching speed of the device and time constant of the load. The variable switching frequency operation is considered as the only disadvantage. 


\subsection{Linear Control}

In the linear control scheme [3], the actual currents are compared to the references and the errors are processed by conventional proportional-integral controllers to provide a reference control signal for a PWM modulator. This produces constant-frequency with pulse width-modulated gate signals for the converter switches. The controller parameters are adjusted to optimize the system transient response. The implementation of linear controller is relatively straightforward using standard integrated circuits.

\subsection{Predictive Control}

The predictive control [1] predicts the current-error-vector at the beginning of each modulation period. The prediction is based on the error and the load variables. The predicted voltage vector is used by the PWM pulse generator during the next modulation cycle and hence minimizes the error. This technique uses more information along with regulator error signal and hence produces output response from the converters. The predictive regulators are particularly suitable for digital implementation. Where the signal acquisition can be discrete and suitable for implementation in digital which may provide good calculation power needed for effective control of the converter operation and improve the performance.

\subsection{Introduction}

\section{Fuzzy Logic Controller}

Many industrial processes do not permit precise mathematical modelling. Mathematical modelling is required for classical control theory approaches. The industrial processes, which do not allow mathematical modelling, may have non-linear relation between system state and the control. Some confused industrial processes or system are controlled by human operators who are capable of controlling under insufficient and inadequate information using the qualitative information and thumb rules. Fuzzy logic [4] works similar to the above human operator controlling a plant or process. Fuzzy logic is mathematical tool to simulate human thinking process and is not really "fuzzy". A fuzzy logic controller has a set of rules, which is used to calculate the final control action. Each rule is linguistic expression about the control action to be taken in response to a given set of process conditions. The rules have the following general format

\section{IF <CONDITION > THEN <ACTION>}

Fuzzification of the variables used by the fuzzy logic controller based on the knowledge attained about the process. The inference, which is composed of several rules, which forms the rule base. The inference process proceeds from the initial conditions to the conclusions, and then to the logical sum. The defuzzification operation that unifies the result of the rule base and calculate a crisp final value of the output.

\subsection{Fuzzy Logic Controller for Boost converter}

The proposed Fuzzy Logic control system is a two input one output Fuzzy Logic Controller [6]. As a traditional way the two inputs are selected as "error" and "change in error". The output voltage was sensed and it was compared with the reference voltage or set point. The "Error" is difference between reference value and actual value. Similarly "Change in Error" is the difference between present error and previous error.

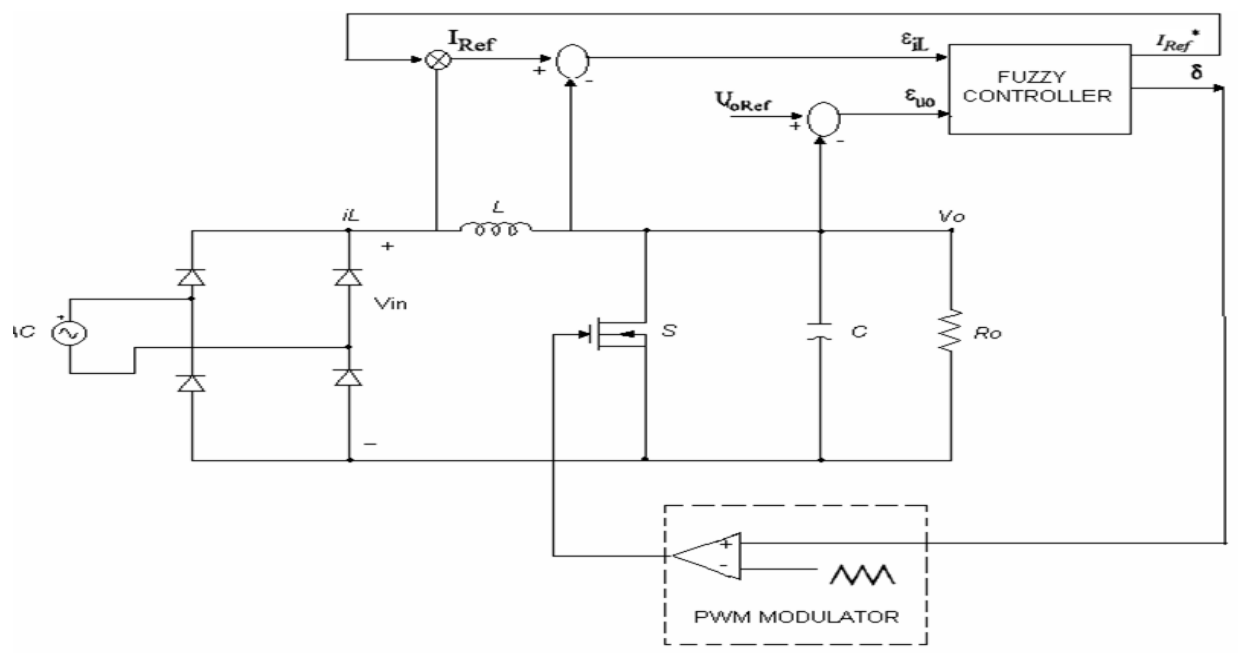

Fig -1: Boost Converter with Fuzzy Control

The output membership function is "Change in Control Voltage". The triangular membership function and its arrangement for Error, Change in Error and Control Voltage are shown below with its FAM table and 
surface View. FLC is one of the most successful applications of fuzzy set theory, introduced by Zadeh in 1965 [8]. Its major features are the use of linguistic variables rather than numerical variables. Linguistic variable, defined as variables whose values are sentences in a natural language (such as small and large), may be represented by fuzzy set.

A fuzzy set is an extension of a crisp set where an element can only belong to a set (full membership) or not belong at all (no membership). Fuzzy sets allow partial membership which means that an element may partially belong to more than one set. A fuzzy set $A$ is characterized by a membership function $\mu_{\mathrm{A}}$ that assigns to each object in a given class a grade of membership to the set. Of course, the grade of membership can range from 0 (no membership) to 1 (full membership); we therefore write

$$
\mu_{\mathrm{A}}=X \rightarrow[0,1]
$$

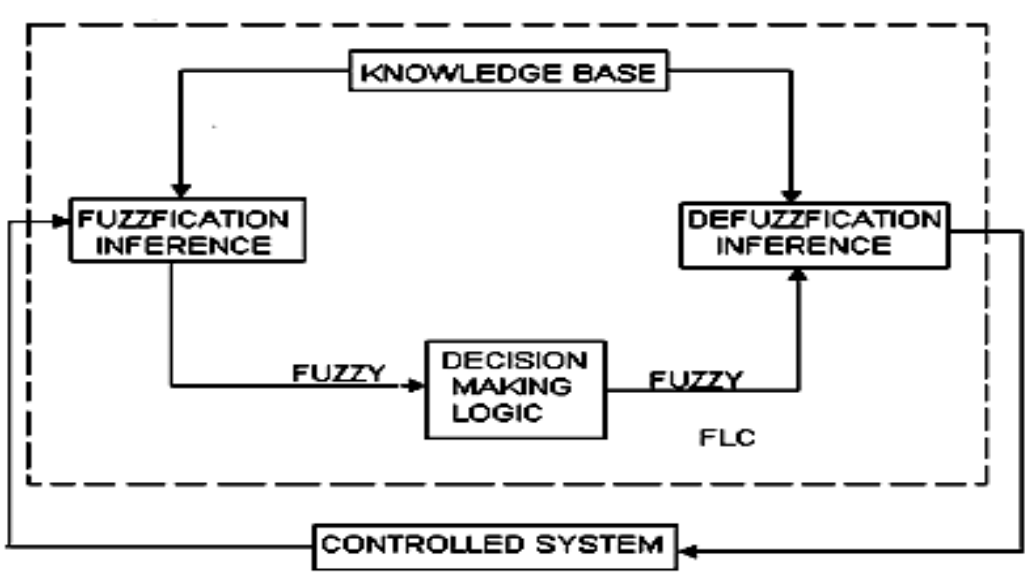

Fig. 2 Basic Configuration of FLC

The general structure of an FLC is represented in Fig. 2 and comprises four principal components: 1) a fuzzyfication interface which converts input data into suitable linguistic values; 2) a knowledge base which consists of a data base with the necessary linguistic definitions and control rule set; 3) a decision making logic which, simulating a human decision process, infers the fuzzy control action from the knowledge of the control rules and the linguistic variable definitions; and 4) a defuzzyfication interface which yields a non fuzzy control action from an inferred fuzzy control action.

\subsection{DESIGN OF R, L, C}

For the given specification of the converter, procedure to design the value of R, L, and C is as follows. In general, current ripple is considered for designing the value of inductance L. Voltage ripple is considered for designing the value of capacitance $\mathrm{C}$.

The maximum ripple current $\left[\mathrm{I}_{\text {rip max }}\right]$ for this converter is given as

$$
I_{\text {rip } \max }=\frac{V}{4 f_{s} L}
$$

Where

$$
\begin{aligned}
& \text { V- Output voltage } \\
& \mathrm{f}_{\mathrm{s}}-\text { Switching frequency }
\end{aligned}
$$

$$
\text { Let } \mathrm{I}_{\text {rip } \max }=1 \mathrm{~A}
$$

Substituting this in eqn (1) the value of the inductance has been calculated as

$$
\begin{aligned}
L & =\frac{100}{4 X .1 X 160000} \\
& =1.5 \mathrm{MH}
\end{aligned}
$$

The voltage ripple $\left(\mathrm{V}_{\text {ripple}}\right)$ for this converter is given as 


$$
\mathrm{V}_{\text {ripple }}=\frac{I}{2 \omega C}
$$

Where
I- Output current
C-Capacitance

The output current I can be calculated as I $=\frac{\text { outputpower }}{\text { outputvoltage }}$

$$
\begin{aligned}
I & =100 / 100 \\
& =1 \mathrm{Amps}
\end{aligned}
$$

Let $\mathrm{V}_{\text {ripple }}=0.8$ volts

Substituting $\mathrm{V}_{\text {ripple }}$ and $\mathrm{I}$ in eqn (2) the value of $\mathrm{C}$ has been calculated as follows.

$$
\begin{aligned}
\text { C } & =\frac{1}{2 \mathrm{X} 2 \Pi \times 50 \times .8} \\
& =2 \mathrm{mF}
\end{aligned}
$$

\subsection{Fuzzy Controller Structure}

The first important step in the fuzzy controller definition is the choice of the input variables. In order to improve operation, we need additional information on the energy stored in the converter, i.e., an inductor current must be sensed. This approach allows substantial improvement of converter dynamic performances similarly to that obtained in analog current-controlled converters. Accordingly, in the proposed fuzzy controller we use three input variables: 1) output voltage error 2) inductor current error and 3) inductor current which is used for current limiting.
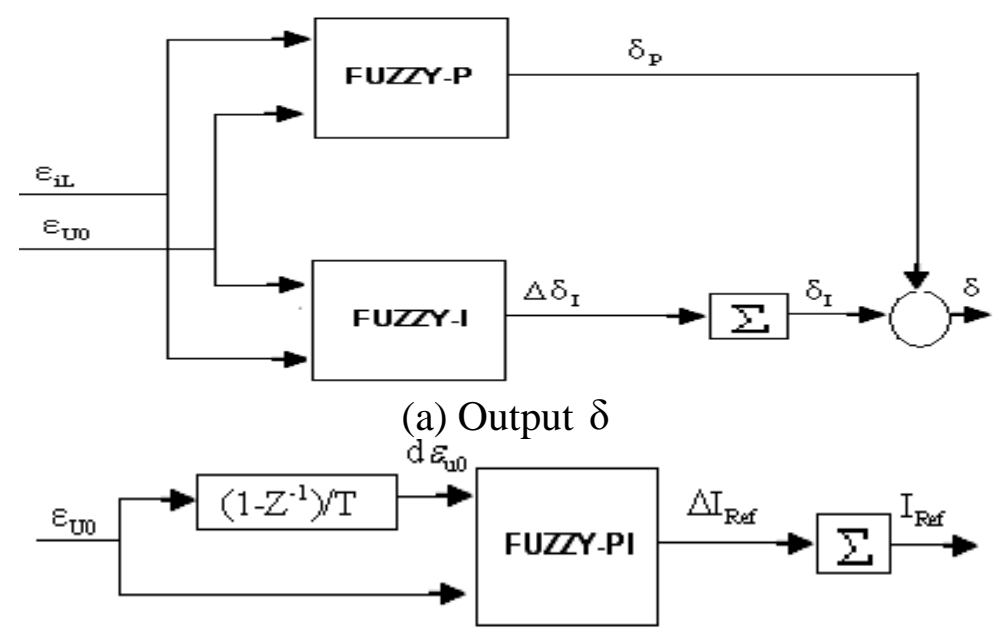

(b) Output $\mathrm{I}_{\mathrm{REF}}$

Fig. 3: Fuzzy Controller Structure

As far as controller output $\delta$ is concerned, a block diagram of the fuzzy controller structure is shown in Fig.3.(a). The controller output variable is the switch duty-cycle, which is obtained by adding the outputs of two different fuzzy controllers: one ("Fuzzy- P",) gives the proportional part $\delta_{\mathrm{p}}$, of the duty-cycle as a function of $\varepsilon_{\mathrm{IL}}$ and $\varepsilon_{\mathrm{UO}}$ the other ("Fuzzy-I") gives the increment, which is then integrated to provide integral term $\delta_{\mathrm{I}}$, of the duty-cycle $\delta$. This structure allows selection of independent control laws for the "proportional" part and the "integral" part of the duty-cycle.

The input current reference is not available to the controller as an external signal but must be internally generated. In a PFP the current reference waveform is a replica of the rectified input voltage, the controller must provide a proper scale factor $\mathrm{I}_{\mathrm{Ref}}$ calculated from the output voltage error so as to keep it to zero. 


\subsection{Membership Function}

Fuzzy sets [8] must be defined for each input and output variable. As shown in Fig 4, five fuzzy subsets [positive big (PB), positive small (PS), zero (ZE), negative small (NS), and negative big (NB)] have been chosen for input variables $\varepsilon_{\mathrm{I}}$ and $\varepsilon_{\mathrm{U}}$ while only two fuzzy subsets [normal operation (NORM) and current limit (LIMIT)] have been selected for the input current since the purpose is to handle only the current limit condition. For the output variables, seven fuzzy subsets have been used (PB, PM, PS, ZE, NS, NM, and NB) in order to smooth the control action. As shown in Fig 5, triangular and trapezoidal shapes have been adopted for the membership functions; the value of each input and output variable is normalized in $[1,1]$ by using suitable scale factors.

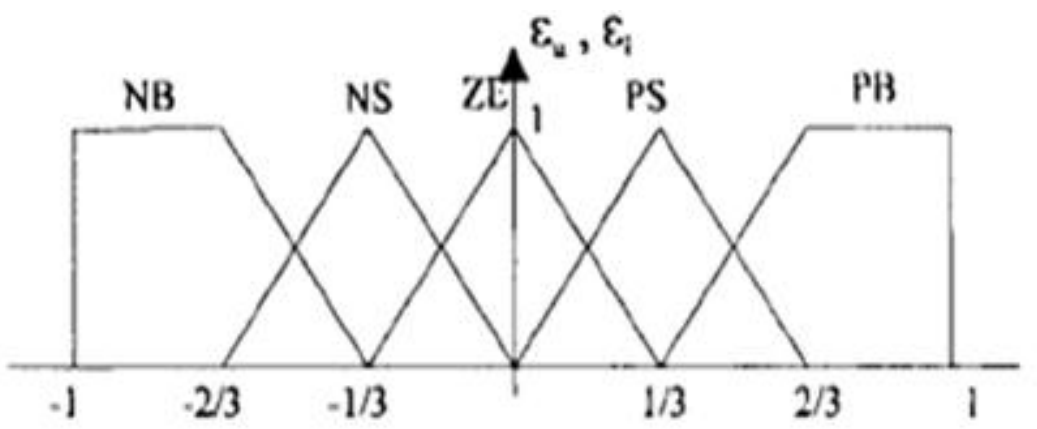

Fig. 4: Error in Output Voltage

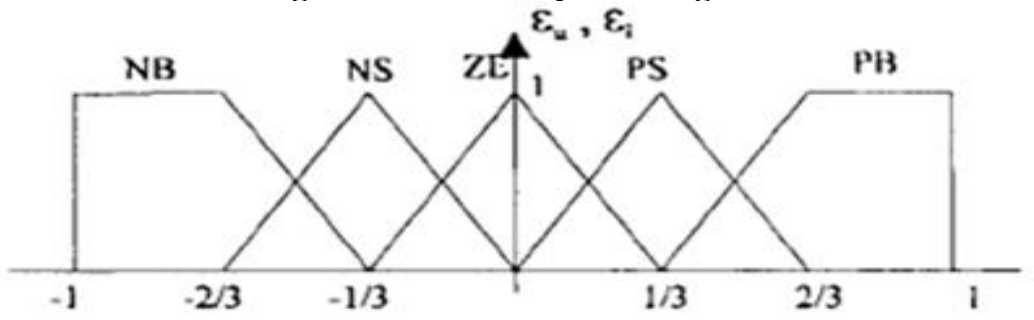

Fig. 5: Change of Error in Output Voltage

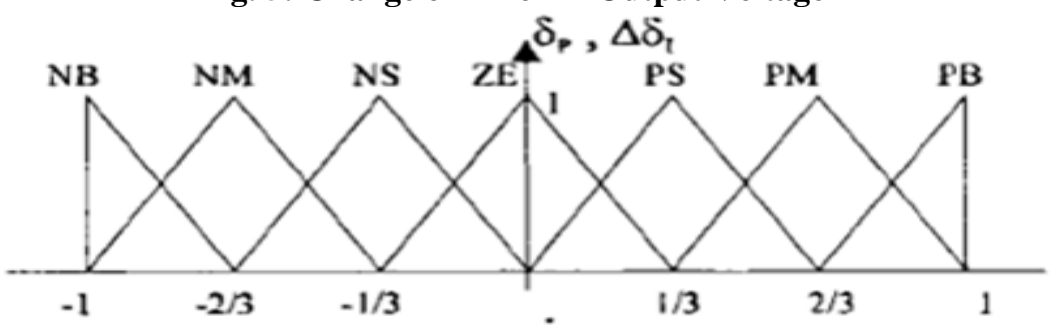

Fig 6: Output Membership Function

\subsection{FAM Table}

\begin{tabular}{|c|c|c|c|c|c|}
\hline$\varepsilon_{\text {iL }} \varepsilon_{\text {uo }}$ & NE & $P S$ & $Z E$ & $N S$ & $P B$ \\
\hline$P B$ & NE & $P S$ & $P M$ & $P B$ & $P B$ \\
\hline$P S$ & NE & $Z E$ & $P S$ & $P M$ & $P B$ \\
\hline$Z E$ & NE & $N S$ & $Z E$ & $P S$ & $P B$ \\
\hline NS & NE & NM & NS & $Z E$ & $P B$ \\
\hline NE & NE & NE & NM & $N S$ & $P B$ \\
\hline
\end{tabular}

Table -1: Rule Table for Fuzzy-P 


\begin{tabular}{|c||c|l|l|l|l|}
\hline$\varepsilon_{\text {iL }}$ uo & $N E$ & $P S$ & $Z E$ & $N S$ & $P E$ \\
\hline \hline$P E$ & $Z E$ & $P S$ & $P M$ & $P S$ & $Z E$ \\
\hline$P S$ & $Z E$ & $Z E$ & $P S$ & $P M$ & $Z E$ \\
\hline$Z E$ & $Z E$ & $N S$ & $Z E$ & $P S$ & $Z E$ \\
\hline$N S$ & $Z E$ & $N M$ & $N S$ & $Z E$ & $Z E$ \\
\hline$N E$ & $Z E$ & $N S$ & $N M$ & $N S$ & $Z E$ \\
\hline
\end{tabular}

Table -2: Rule Table for Fuzzy-I

\begin{tabular}{|c||c|l|l|l|l|}
\hline \multicolumn{1}{|c||}{$d \varepsilon_{\text {uolv }}$} & NB & $P S$ & $Z E$ & NS & PB \\
\hline \hline PB & $Z E$ & $P S$ & $P M$ & $P B$ & $P B$ \\
\hline$P S$ & $N S$ & $Z E$ & $P S$ & $P M$ & $P B$ \\
\hline$Z E$ & $N M$ & $N S$ & $Z E$ & $P S$ & $P M$ \\
\hline$N S$ & $N B$ & $N M$ & $N S$ & $Z E$ & $P S$ \\
\hline$N B$ & $N B$ & $N B$ & $N M$ & $N S$ & $Z E$ \\
\hline
\end{tabular}

Table -3: Rule Table for Fuzzy-PI

\subsection{Introduction}

\section{Simulation Results And Analysis}

The boost converter with fuzzy logic control discussed in the previous session is validated for the following parameters using MATLAB / SIMULINK Software as shown in fig 7.

\subsection{Specifications of converter used}

The boost converter based ac to dc converter has been simulated with the following specifications. .

\begin{tabular}{|l|l|}
\hline Source voltage & 55 Volts (rms) \\
\hline Output voltage & 100 Volts (avg) \\
\hline Output power & $100 \mathrm{~W}$ \\
\hline Switching frequency & $160 \mathrm{KHz}$ \\
\hline Line current THD & $\leq 5 \%$ \\
\hline Inductance & $1.5 \mathrm{MH}$ \\
\hline Capacitance & $2 \mathrm{mC}$ \\
\hline
\end{tabular}

Table 1: Specification of Converter Used 


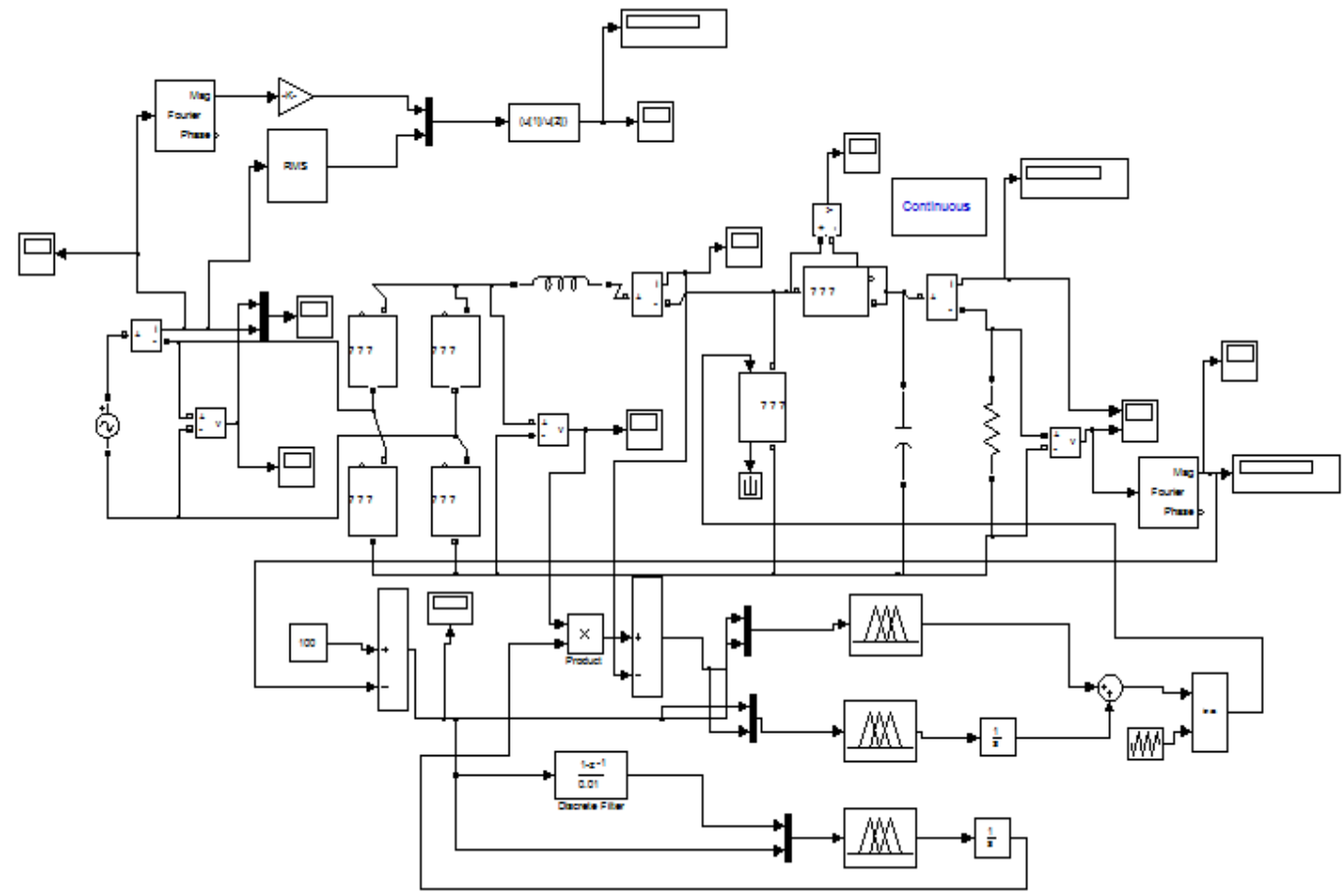

Fig 7: Simulation Circuit of Boost Converter with Fuzzy Logic Control

\subsection{Simulation Results}

The simulation results for the various cases are listed below.

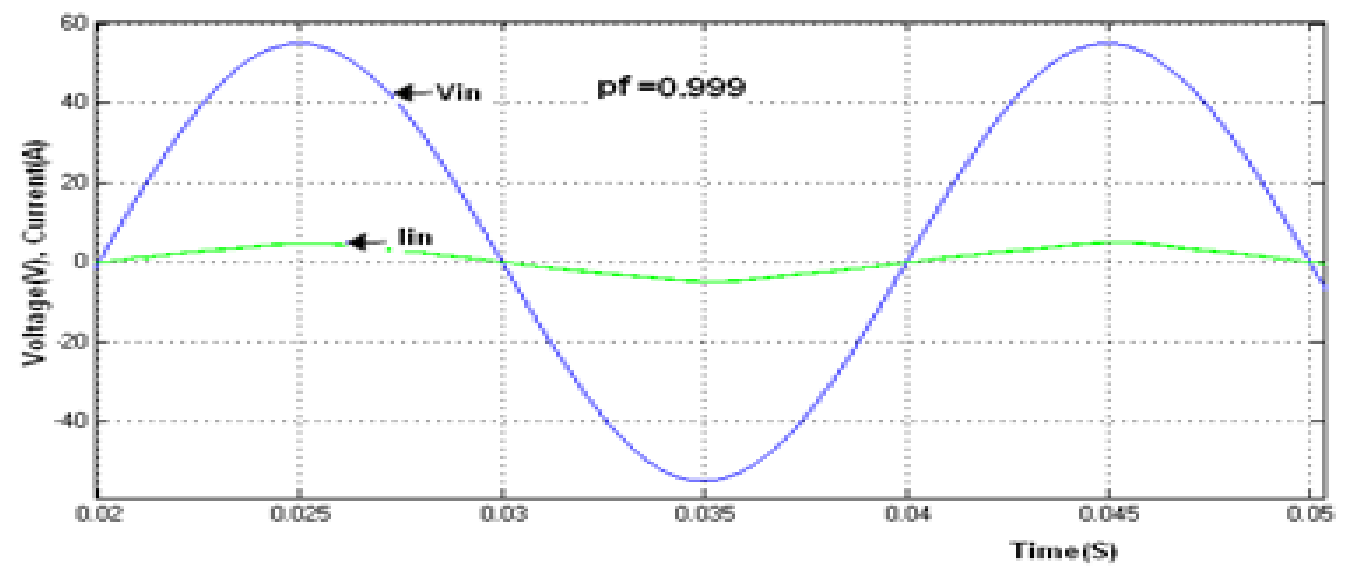

Fig 8: Input Voltage and Current Waveform at full load

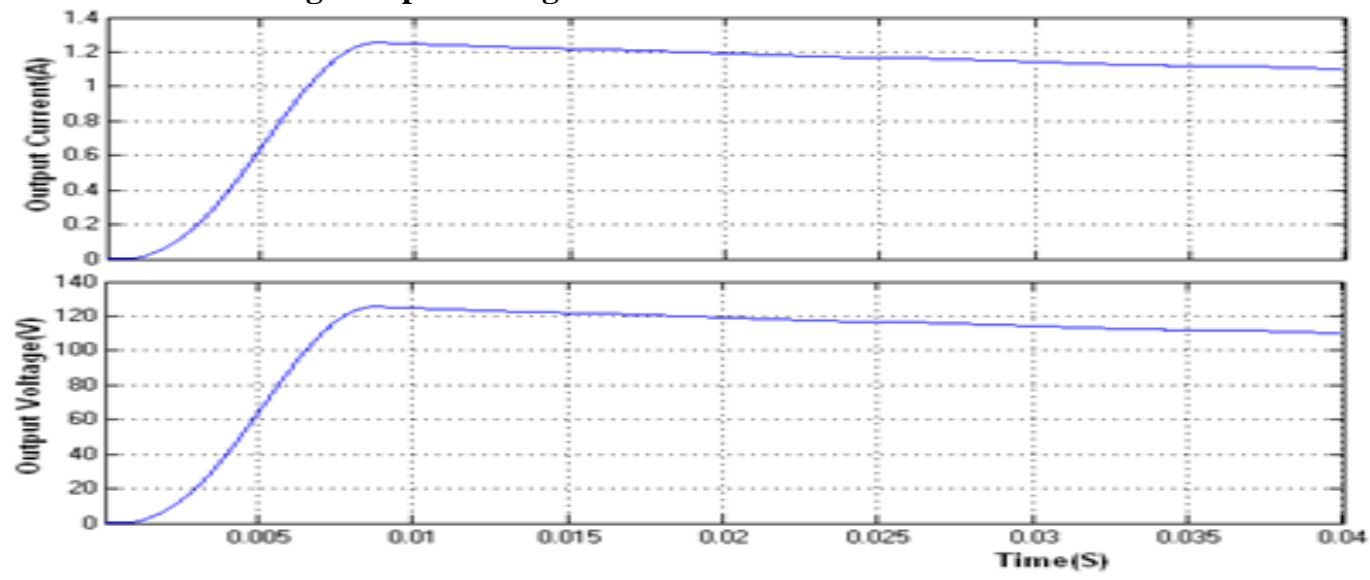

Fig 9: Output Current and Voltage Waveform at full load 


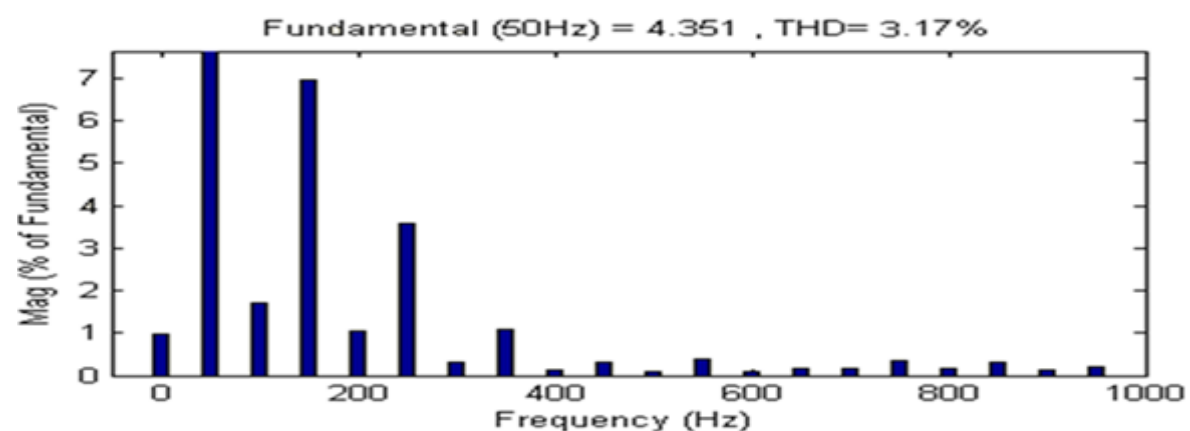

Fig 10: Harmonic Spectrum of Input Current Waveform at full load

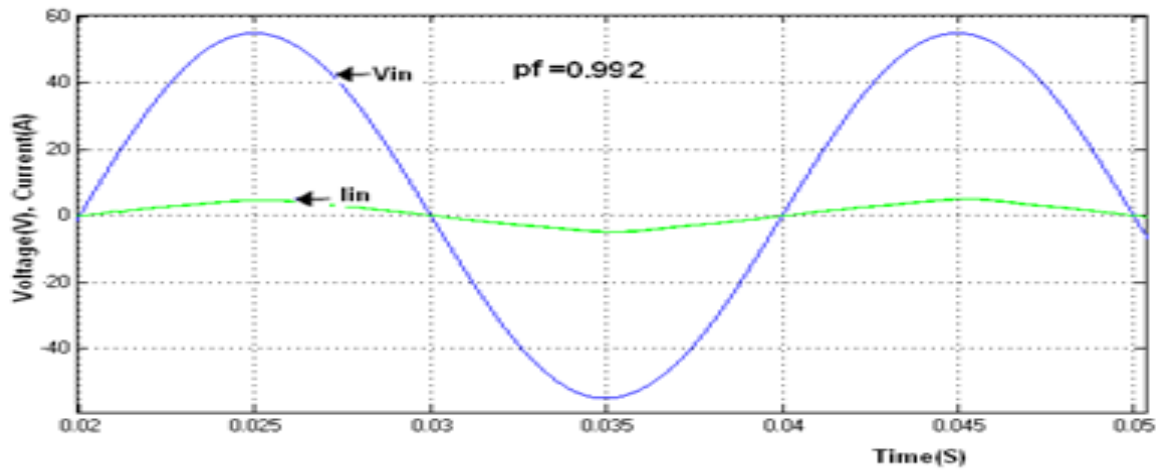

Fig 11: Input Voltages and Current Waveform at Different Load

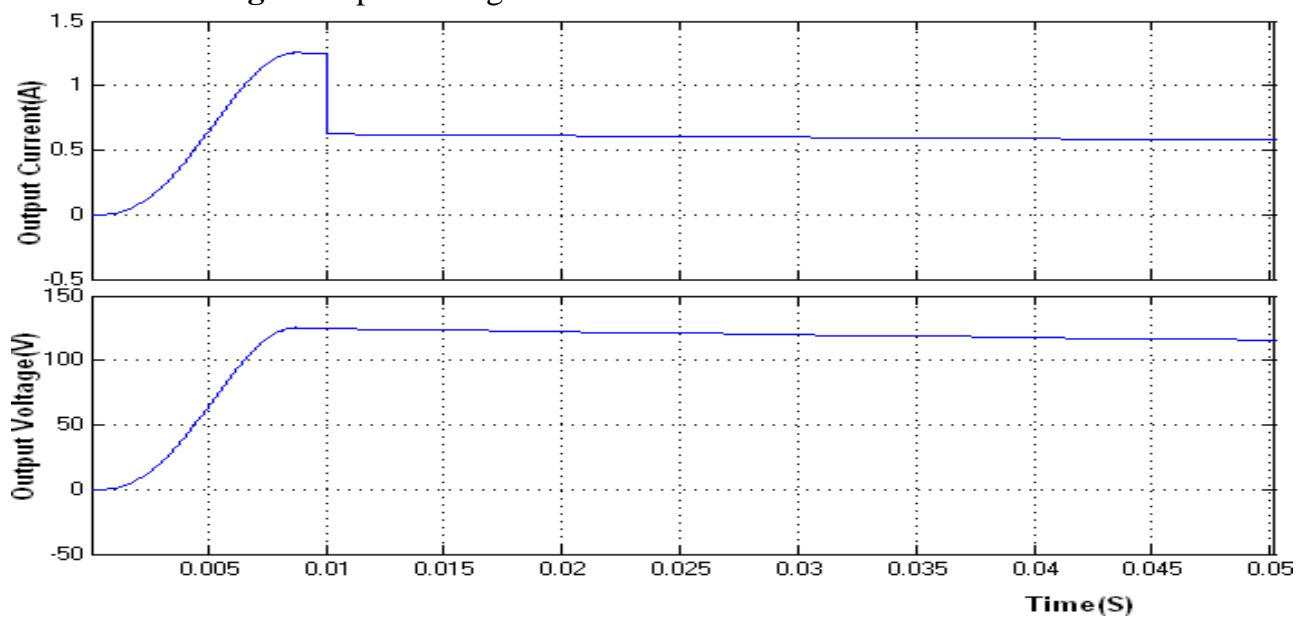

Fig 12: Output Current and Voltage Waveform at Different Load

Fundamental $(50 \mathrm{~Hz})=4.323 . \mathrm{THD}=4.49 \%$

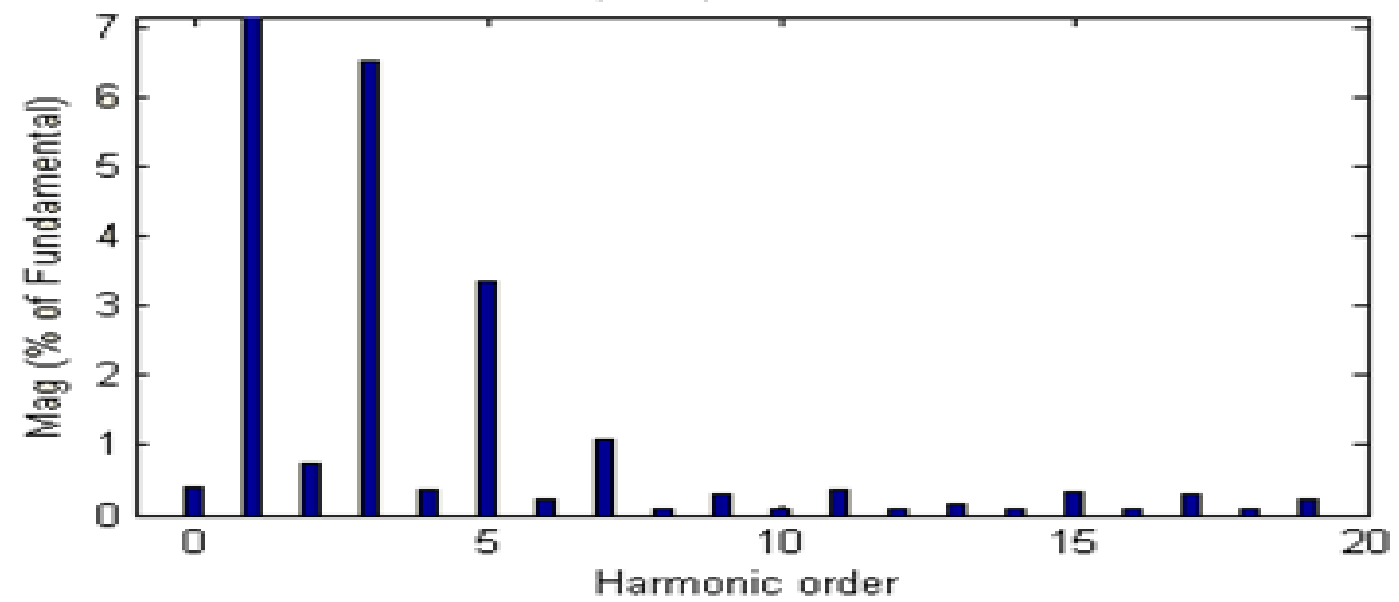

Fig 13: Harmonic Spectrum of Input Current Waveform at Different load 


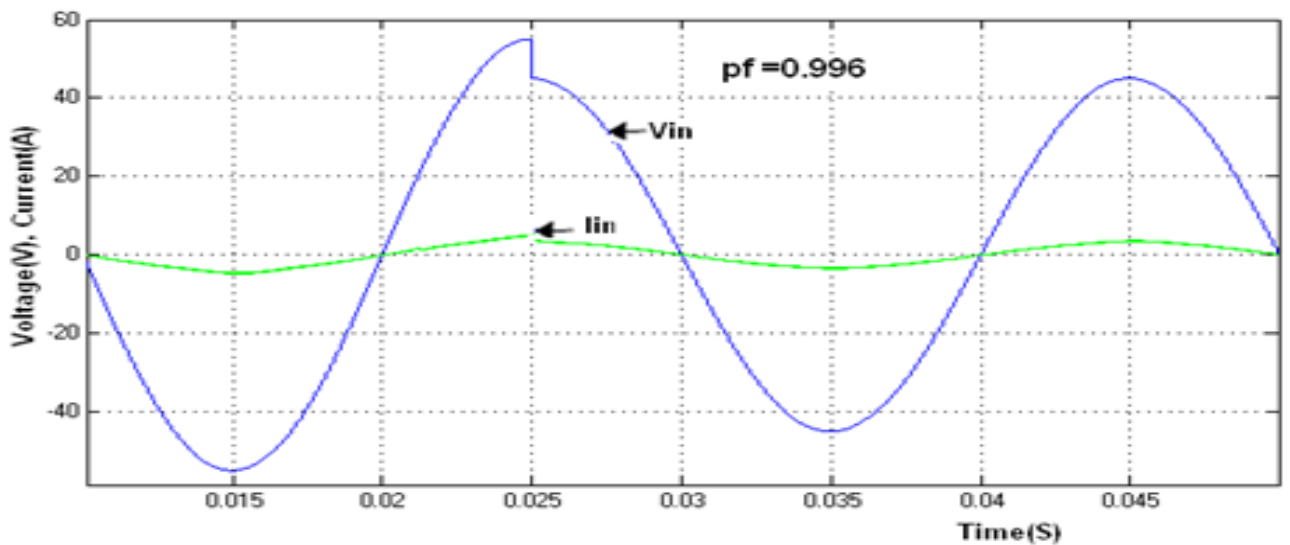

Fig 14: Input Voltage and Current Waveform at Distorted input

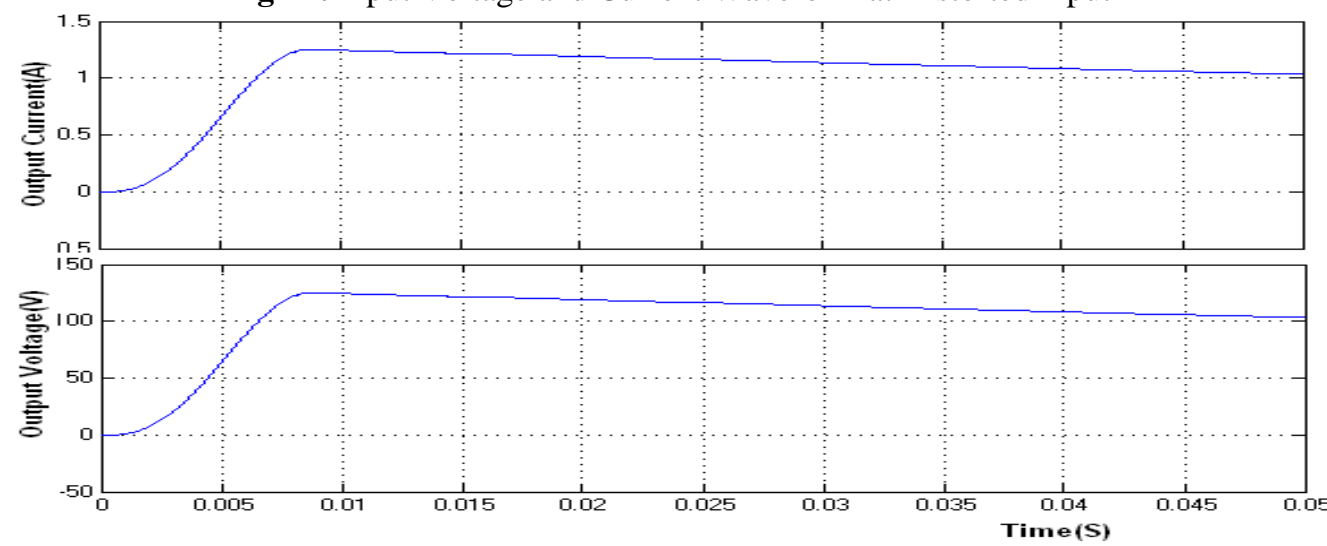

Fig 15: Output Current and Voltage Waveform at Different Load

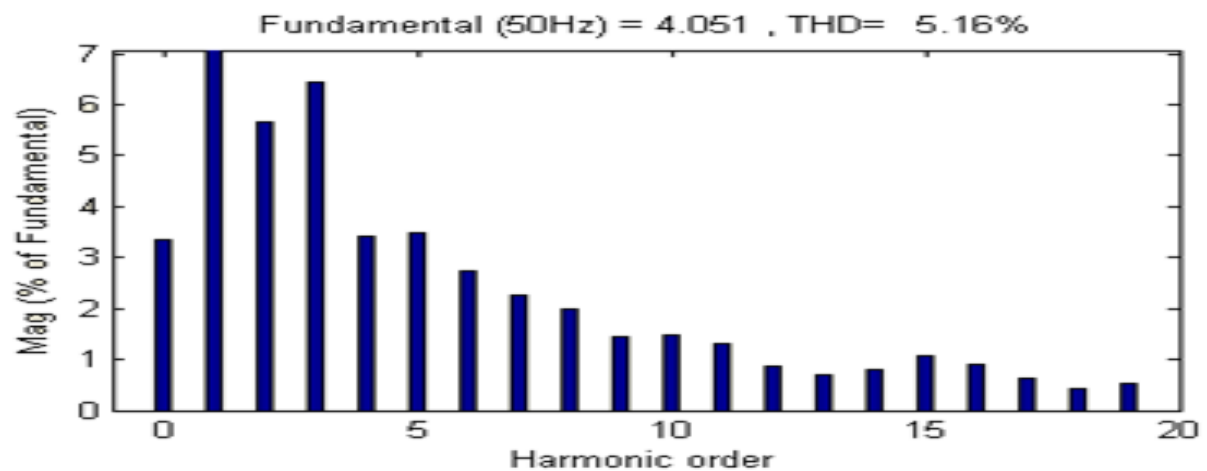

Fig 16: Harmonic Spectrum of Input Current Waveform at distorted output

\begin{tabular}{|c|c|c|}
\hline Case & Power Factor & $\begin{array}{c}\text { \% Total Harmonic } \\
\text { Distortion }\end{array}$ \\
\hline Full Load & 0.999 & 3.17 \\
\hline Different load & 0.992 & 4.49 \\
\hline Input Distortion & 0.996 & 5.16 \\
\hline
\end{tabular}

Table 4: Power Factor and THD for Different Cases

\section{Conclusion}

Closed loop performance of PFC converters with fuzzy control schemes have been studied and verified through simulation. Simulation results show that the proposed strategy works well and close to unity power factor can be achieved over wide input voltage and load current variation range. The proposed PFC control strategy can achieve sinusoidal current waveform in the transient state for step load change and input voltage change. It has been observed that power factor is maintained near unity (0.99), THD in input current is $\leq 5 \%$ irrespective of the load variation as well as supply voltage variation. 


\section{References}

[1] Wanfeng Zhang, Guang Feng, Yan-Fei Liu and Bin Wu, "A Digital Power Factor Correction (PFC) Control Strategy Optimized for DSP, ”IEEE TRANSACTIONS ON POWER ELECTRONICS, VOL. 19, NO. 6, NOVEMBER 2011.

[2] Fariborz Musavi, Murray Edington, Member, Wilson Eberle and William G. Dunford, "Control Loop Design for a PFC Boost Converter With Ripple Steering," IEEE TRANSACTIONS ON INDUSTRY APPLICATIONS, VOL. 49, NO. 1, JANUARY/FEBRUARY 2013.

[3] Sungsik Park and Sewan Choi, "Soft-Switched CCM Boost Converters With High Voltage Gain for High-Power Applications" IEEE TRANSACTIONS ON POWER ELECTRONICS, VOL. 25, NO. 5, MAY 2010

[4] Faa-Jeng Lin Ming-Shi Huang ; Po-Yi Yeh ; Han-Chang Tsai ; Chi-Hsuan Kuan , "On the use of the describing function in fuzzy controller design for switching dc-dc regulators," IEEE Trans Power Electronics., vol. 13, pp. 213-221, Aug. 2012.

[5] Martinez S., F.H. Gomez M, D.F.., "Fuzzy logic controller for boost converter with active power factor correction ," IEEE Trans. Power Electronics., vol. 13, pp. 814-823, Sept. 2007.

[6] Tam, E.P.W. ; Hui, S.Y.R. Chung, H.S.H "H Development of a fuzzy logic controller for boost rectifier with active power factor correction," correction Power Electronics Specialists Conference, 1999. PESC 99.

[7] Khoshooei, A. Moghani, J.S., "Implementation of a single input fuzzy controller for a high power factor boost rectifier," AFRICON, 2004. 7th AFRICON Conference in Africa 15-17 Sept. 2004

[8] P. mattavelli, S. Buso, G. Spiazzi, P. Tenti “General purpose Fuzzy controller for DC/DC converter” APEC conf. Proc, 1995, Dallus, pp.723-730

[9] P. mattavelli, S. Buso, G. Spiazzi, "Fuzzy control of power factor preregulators,” APEC conf. Proc, 1995.

[10] J. Spangler and A. Behera, "A comparison between hysteretic and fixed frequency Boost converters used for power factor correction," in Proc IEEE Applied Power Electronics Conf. Expo, 1993, pp. 281-286. 